\title{
Contrast Agent Finished Identifier
}

National Cancer Institute

\section{Source}

National Cancer Institute. Contrast Agent Finished Identifier. NCI Thesaurus. Code C69277.

An identifier for a contrast agent for which administration has ended. 